\title{
Long Latency Auditory Potential (P300) Outcomes in a Patient with Vestibular Schwannoma after Cochlear Implant Surgery
}

\author{
Maria Stella Arantes do Amaral1,2*, Victor Goiris Calderaro ${ }^{3,4}$, Henrique Furlan Pauna1,2, \\ Eduardo Tanaka Massuda1, Ana Cláudia Mirândola Barbosa Reis ${ }^{3}$, Miguel Ângelo Hyppolito ${ }^{1}$
}

${ }^{1}$ Department of Ophthalmology, Otorhinolaryngology, Head and Neck Surgery, Ribeirão Preto Medical School, University of São Paulo, Ribeirão Preto, São Paulo, Brazil

${ }^{2}$ Postgraduate Program at the Department of Ophthalmology, Otorhinolaryngology, Head and Neck Surgery, Ribeirão Preto Medical School, University of São Paulo, Ribeirão Preto, São Paulo, Brazil

${ }^{3}$ Department of Health Sciences-RCS—Ribeirão Preto Medical School, University of São Paulo, Ribeirão Preto, São Paulo, Brazil ${ }^{4}$ Postgraduate Program at the Department of Health Sciences-RCS-Ribeirão Preto Medical School, University of São Paulo, Ribeirão Preto, São Paulo, Brazil

Email: *stella_arantes@yahoo.com

How to cite this paper: do Amaral, M.S.A., Calderaro, V.G., Pauna, H.F., Massuda, E.T., Reis, A.C.M.B. and Hyppolito, M.Â. (2018) Long Latency Auditory Potential (P300) Outcomes in a Patient with Vestibular Schwannoma after Cochlear Implant Surgery. Case Reports in Clinical Medicine, 7, 343-348. https://doi.org/10.4236/crcm.2018.75031

Received: April 3, 2018

Accepted: May 12, 2018

Published: May 15, 2018

Copyright $\odot 2018$ by authors and Scientific Research Publishing Inc. This work is licensed under the Creative Commons Attribution International License (CC BY 4.0).

http://creativecommons.org/licenses/by/4.0/

(c) (7) Open Access

\begin{abstract}
Background: Neurofibromatosis type 2 (NF2) is a rare syndrome and it is usually presented with bilateral vestibular schwannomas (VS), multiple meningiomas, and other types of tumors associated to peripheral nerves. Hearing loss is one of its leading manifestations, and surgery for removal of the tumor is often required. Cochlear implant (CI) surgery is an option for auditory rehabilitation and long latency auditory potentials (P300) are becoming a very useful tool to assess hearing outcomes. Objective: To verify the presence of P300 waves during auditory and cortical function assessment in a patient submitted to VS removal and CI surgery. Design: Retrospective chart review. Case Report: A 62 years old male patient, presented at the clinic with a bilateral severe to profound hearing loss, worst at the right side. MRI scan revealed bilateral expansive tumor within the internal auditory canal expanding to cerebellopontine angle, suggestive of VS. Tumor was removed at the right side, and CI surgery was indicated for the left ear. P300 tests were performed pre-operatively, at the moment of activation, and 6 months post-operatively. After CI activation, P300 waves appeared, and presented reduced latency and increased amplitude after 6 months of CI use. Conclusion: P300 waves appear to be dependent on the auditory stimulus to be generated, showing that it can be a useful tool to estimate improvement in cortical cognitive function after restoring hearing through CI surgery after VS removal.
\end{abstract}




\section{Keywords}

Audiometry, Cochlear Implant, Sensorineural Hearing Loss, Deafness, Schwannoma

\section{Introduction}

Schwannomas are benign tumors derived from Schwann cells. They are often encapsulated and connected to nerve tissue. Microscopic examination reveals a combination of two patterns, Antoni A and B, with elongated cells and regular oval nuclei. Local recurrence is common in cases of incomplete tumor removal. The VIII cranial nerve ranks first among involved sites, accounting for $80 \%$ of the cases [1]. Bilateral vestibular schwannomas (VS) are often found in patients with neurofibromatosis type 2 (NF2), and bilateral hearing loss is usually seen [2]. Furthermore, NF2 treatment is usually multidisciplinary and auditory rehabilitation can be achieved with cochlear implant (CI) or auditory brainstem implant [2].

Event-related cortical potentials are brain response phenomena that can be either spontaneous or stimulated. Evoked potentials are classified as short, medium, or long, according to their temporally latency, from the onset of the stimulus. Long-latency auditory-evoked potentials (P300) are waves with both negative and positive polarity that appear between 60 and 600 milliseconds after the stimulus. The components of these potentials are known as N1, P2, N2, and P3 [3] [4] [5].

The P300 is a cortical potential related to an event that is the individual's expectation of a visual or auditory stimulus. This potential is the result of the focalization of attention to rare stimuli presented within other frequent stimuli, which is known as the Oddball Paradigm. These potentials can be used to investigate attention and recent memory, which could provide useful information with regard to the cortical processing time from the onset of a visual or auditory stimulus [3] [5] [6] [7].

It is possible that the central process in the auditory cortex plays an important role in the existing and inexplicable variability in the benefits of cochlear implants, especially when considering the prolongation of the latency of N1, P2, and P300 waves in comparison with normal hearing individuals. Cochlear implant users present small N1 and P2 amplitudes in response to all spoken signals, suggesting that there is a relationship between the P300 amplitude and the magnitude of speech recognition [8] [9].

This paper presents a case of a patient with a bilateral vestibular schwannoma, who underwent to CI surgery. A P300 auditory examination was performed to assess auditory rehabilitation.

\section{Case Report}

This case report was approved by the Institutional Ethics Committee and in- 
formed consent was obtained from the patient and his relatives.

A 62 years old male patient presented at the clinic with progressive bilateral hearing loss, which had worsened for the past 5 years. Hearing loss was worse on the right side and patient also complained of tinnitus and occasional vertigo. Audiological evaluation revealed profound sensorineural hearing loss on the right ear and severe hearing loss on the left ear. He also presented many meningiomas in his body. Although these symptoms, patient had no other sign of neurological disorders.

Patient was fitted with bilateral hearing aids, with limited benefit. Further investigation with MRI scan revealed a bilateral vestibular schwannoma, which was larger on the right ear and classified as T4A on the right ear and T3B on the left ear, according to Koos [9]. Definitive diagnosis was bilateral vestibular schwannoma secondary to neurofibromatosis type 2 (Figure 1).

Patient was submitted to otologic surgery to remove the tumor on his right ear, however with post-operative anacusis facial palsy of the right side. Because the patient was still complaining hearing loss, CI surgery was proposed for his left ear, which was performed, and a Digisonic ${ }^{\star}$ SP Evo device (Neurelec, France) was implanted (Figure 2). Prior to surgery, P300 was obtained using the Navigator $\mathrm{Pro}^{\oplus}$ device (Bio-logic Systems Corp, Illinois, USA), and electrodes were positioned according to the method proposed by Jasper [10]. The active electrodes were positioned at $\mathrm{Cz}$ and connected to entrance 1 on the preamplifier in channels 1 and 2, respectively (jumper). The reference electrodes were placed on the lobes of the right and left ears, respectively (A1 and A2) and were then linked and connected to entrance 2 in channels 1 and 2 of the preamplifier, with the ground electrode positioned on $F p z$. The stimulus that was used was a tone burst at frequencies of $1000 \mathrm{~Hz}$ for the repetitive stimuli and $200 \mathrm{~Hz}$ for the rare stimuli. The results of these examinations are presented in Table 1.

Table 1. Results of the P300 before the CI surgery (pre-CI), immediately after CI activation, and 6 months after CI surgery.

\begin{tabular}{cccc}
\hline \multicolumn{4}{c}{ P300 results pre-CI } \\
\hline $\begin{array}{c}\text { Latency CzA1 } \\
(\mathrm{ms})\end{array}$ & $\begin{array}{c}\text { Latency CzA2 } \\
(\mathrm{ms})\end{array}$ & $\begin{array}{c}\text { Amplitude CzA1 } \\
(\mu \mathrm{V})\end{array}$ & $\begin{array}{c}\text { Amplitude CzA2 } \\
(\mu \mathrm{V})\end{array}$ \\
absent & absent & absent & absent \\
& P300 results during CI activation & \\
Latency CzA1 & $\begin{array}{c}\text { Latency CzA2 } \\
(\mathrm{ms})\end{array}$ & $\begin{array}{c}\text { Amplitude CzA1 } \\
(\mu \mathrm{V})\end{array}$ & $\begin{array}{c}\text { Amplitude CzA2 } \\
(\mu \mathrm{V})\end{array}$ \\
393.50 & 386.22 & 1.10 & 1.34 \\
& P300 results after 6 & months CI surgery & \\
Latency CzA1 & Latency CzA2 & Amplitude CzA1 & Amplitude CzA2 \\
$(\mathrm{ms})$ & $(\mathrm{ms})$ & $(\mu \mathrm{V})$ & $(\mu \mathrm{V})$ \\
319.83 & 331.28 & 6.22 & 4.38 \\
\hline
\end{tabular}

Legend: $\mathrm{CI}=$ cochlear implant; $\mathrm{ms}=$ milliseconds; $\mu \mathrm{V}=$ microvolts. 


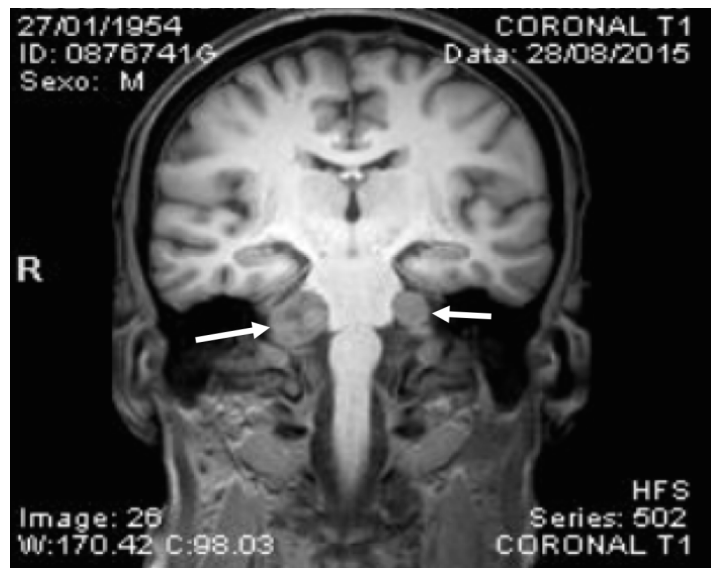

Figure 1. MRI scan (coronal view) of the patient prior to first surgery to remove the vestibular schwannoma on the right ear. Note bilateral expansive lesions at the cerebellopontine angle (arrows). It is notable the difference between both sides, as we can observe how the lesion at the right ear is larger than the one at the left ear.

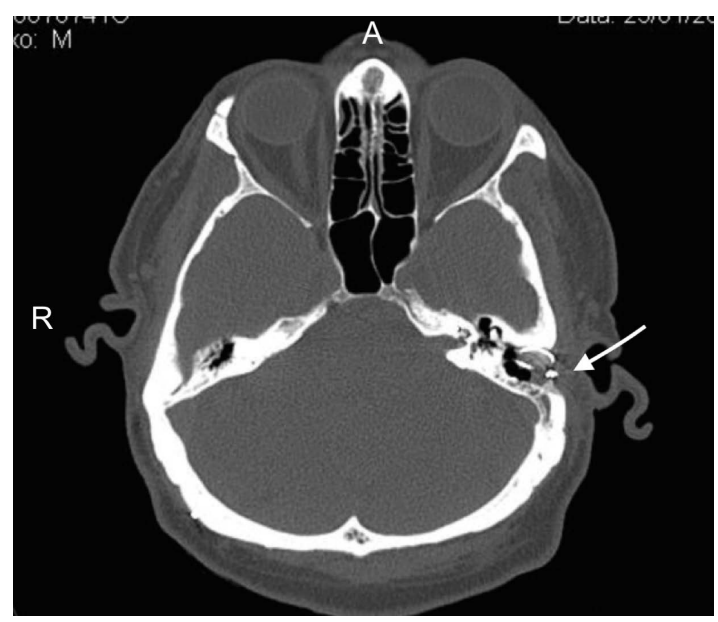

Figure 2. CT scan (axial view) after the CI surgery on the left ear (arrow).

The P300 waves that were absent before the cochlear implantation were immediately registered after the CI activation (at the same day), and again after 6 months. Furthermore, the P300 wave latency decreased and the amplitude increased after 6 months of the processor use. Three months after activation of the $\mathrm{CI}$, the patient recognized all Ling sounds, recognized and understood words and sentences, and was satisfied with the CI.

\section{Discussion}

Vestibular Schwannoma has been recognized as a pathologic entity for at least 200 years and represent around $90 \%$ of the cases of cerebellopontine angle tumors [8]. Surgical treatment is mostly curative in cases of complete removal of 
the tumor [1]. However, any damage to cochlear portion of the VIII cranial nerve can evolve to hearing loss, which may cause several changes in P300 waves. Such cases are usually treated with CI.

When the CI is activated, sound is converted into electrical stimulation and auditory function is reacquired. Fjell and Walhovd observed that the latency of the P300 waves represents an individual's level of cognition and is associated with the speed of the evaluation process of the stimulus in the central nervous system. Another interpretation, however, is that, the amplitude of the P300 could be related to the number of neurons that are recruited to carry out this cognitive task [11].

The reduction in latency and the increase in amplitude of P300 waves that was seen in our patient are according to the literature. It is suggested that P300 is a tool to evaluate the auditory abilities of attention, perception, discrimination, and immediate memory [4] [6] [11]. These findings, along with those of Kelly et al., in which 12 participants who had been using a CI for a period of 1.3 to 5.2 years were compared to patients who were using hearing aids, showed that $\mathrm{CI}$ users exhibit a shorter P300 latency [12].

Few studies evaluated the use of auditory event-related potentials in CI users. They show that the mean latency responses disappear in the majority of patients, remaining only in the patients with excellent performance with the CI. These studies also demonstrate that the responses to P300 remain similar to normal hearing individuals, with amplitudes that positively correlate with scores on speech perception tasks, in speech-in-noise tests [12] [13] [14]. This suggests, therefore, that CI users have difficulty in automatically perceiving speech-in-noise, which is an improvement related to central auditory processing, as indicated by the presence of P300 waves [14]. The present case report reinforces the findings of Soshi et al., in which the evolution of P300 responses from the beginning of auditory re-establishment to 6 months of effective use of CI includes a reduced latency and an increased amplitude and is correlated with a better auditory performance [13].

\section{Conclusion}

As a tool to evaluate cortical function, P300 is an objective and non-invasive test that can be used in clinical practice when cortical function must be evaluated. In this case, we showed that the cortical function improved after 6 months of auditory stimulation by the $\mathrm{CI}$ and was associated with an increase in amplitude and a reduction in wave latency.

\section{References}

[1] Pauna, H.F., Carvalho, G.M., Guimarães, A.C., Maunsell, R.C.K. and Sakano, E. (2013) Schwannoma of the Nasal Septum: Evaluation of Unilateral Nasal Mass. Brazilian Journal of Otorhinolaryngology, 79, 403. https://doi.org/10.5935/1808-8694.20130070

[2] Rosahl, S., Bohr, C., Lell, M. and Iro, H. (2017) Diagnosis and Therapy of Vestibular 
Schwannomas-An Interdisciplinary Challenge. GMS Current Topics in Otorhinolaryngology_Head and Neck Surgery, 16, Doc03.

[3] Duarte, J.L., Alvarenga, K.F. and Costa, O.A. (2004) P300 Cognitive Potential in the Free Field: Applicability of the Test. Brazilian Journal of Otorhinolaryngology, 70, 780-785. https://doi.org/10.1590/S0034-72992004000600013

[4] Franco, G.M. (2001) The Cognitive Evoked Potential in Normal Adults. Arquivos de Neuro-Psiquiatria, 59, 198-200. https://doi.org/10.1590/S0004-282X2001000200008

[5] Bevilacqua, M.C., Martinez, M.A.N., Balen, S.A., Pupo, A.C., Reis, A.C.M. and Frota, S. (2011) Audiology Treaty. São Paulo: Santos, 15, 231-260.

[6] Polich, J. (1991) P300 in Clinical Applications: Meaning, Method, and Measurement. American Journal of EEG Technology, 31, 201-231.

[7] Massa, C.G.P., Rabelo, C.M., Matas, C.G., Schochat, E. and Samelli, A.G. (2011) P300 with Verbal and Non-Verbal Stimuli in Normal Hearing Adults. Brazilian Journal of Otorhinolaryngology, 77, 686-690. https://doi.org/10.1590/S1808-86942011000600002

[8] Bento, R.F., Pinna, M.H. and Brito Neto, R.V. (2012) Vestibular Schwannoma: 825 Cases-25 Years of Experience. International Archives of Otorhinolaryngology, 16, 466-475.

[9] Koos, W.T., Spetzler, R.F., Böck, F.W. and Salah, S. (1976) Microsurgery of Cerebellopontine Angle Tumors. In: Koos, W.T., Böck, F.W. and Spetzler, R.F., Eds., Clinical Microneurosurgery, Thieme, Stuttgart, 91-112.

[10] Jasper, H.A. (1958) The Ten-Twenty Electrode System of the International Federation. Electroencephalography and Clinical Neurophysiology, 10, 371-375.

[11] Fjell, A.M. and Walhovd, K.B. (2003) Effects of Auditory Stimulus Intensity and Hearing Threshold on the Relationship among P300, Age and Cognitive Function. Clinical Neurophysiology, 114, 799-807. https://doi.org/10.1016/S1388-2457(03)00030-0

[12] Kelly, A.S., Purdy, S.C. and Thorne, P.R. (2005) Electrophysiological and Speech Perception Measures of Auditory Processing in Experienced Adult Cochlear Implant Users. Clinical Neurophysiology, 116, 1235-1246. https://doi.org/10.1016/j.clinph.2005.02.011

[13] Soshi, T., Hisanaga, S., Kodama, N., Kanekama, Y., Samejima, Y., Yumoto, E. and Sekiyama, K. (2014) Event-Related Potentials for Better Speech Perception in Noise by Cochlear Implant Users. Hearing Research, 316, 110-121. https://doi.org/10.1016/j.heares.2014.08.001

[14] Groenen, P.A., Beynon, A.J., Snik, A.F. and van den Broek, P. (1996) Speech-Evoked Cortical Potentials and Speech Recognition in Cochlear Implant Users. Acta Otolaryngologica, 116, 785-790. https://doi.org/10.3109/00016489609137926 